\title{
Perception of Reflective Journaling during Clinical Posting among Nursing Students
}

\author{
Article by Musah K. Toyin ${ }^{1}$, Philip A. Ojo ${ }^{2}$, Okueso Grace Ogba ${ }^{3}$ \\ ${ }^{l}$ Department of Community Health Science, School of Allied Health and Environmental \\ Science, College of Pure and Applied Sciences, Kwara State University, Malete, Nigeria \\ ${ }^{2}$ School of Nursing, University College Hospital, Ibadan, Oyo State, Nigeria \\ ${ }^{3}$ School of Nursing Science, Department of Maternal \& Child Health, Babcock University, \\ Ilishan-Remo, Ogun State, Nigeria \\ E-mail: khadijat.musah@kwasu.edu.ng ${ }^{1}$ or musahtoyin1@gmail.com ${ }^{1}$, \\ philocomet@yahoo.com ${ }^{2}$,graceokueso@gmail.com ${ }^{3}$
}

\begin{abstract}
The aim of the study was to find out about perception of reflective journaling among undergraduate nursing students in Babcock University, Ilisha-Remo, Ogun State, Nigeria. The objectives were to determine the students' perception of reflective journaling and the perceived meaning of reflective journal writing. This study utilized a descriptive research design. Data was collected through self-administered questionnaire. Population of 130 students in 400 and 500 levels were used. Results of the reliability test, using Cronbach's alpha of all the constructs measuring the perception and the explanatory variables were well above the recommended minimum of 0.70. Results revealed that, a significantly higher proportion of the participants have positive perception towards reflective journaling in the undergraduate nursing program in Babcock University. The mean score of perception of reflective journaling was 1.93205. Most of the students were able to correlate theory with practice (96.2\%) with the mean of 1.9615. Data evidences also revealed that, the status of perceived meaning of reflective journaling of nursing students' clinical learning and practice is high. This inference is evident in the fact that overall criterion weighted mean score (1.805147) is greater than the average Likert scale of 1.5.
\end{abstract}

Keywords: Critical thinking, Journaling, Perception, Reflective writing, Nursing Students

\section{Introduction}

Reflection, as defined by Reed, ${ }^{[1]}$ is a process of reviewing an experience of practice in order to describe, analyze, evaluate and to inform learning about practice. It involves opening one's practice for others to examine and require courage and open-mindedness as well as to take on board and act on-criticism ${ }^{[2]}$. There is also the element of critical theory where there is an assumption that reflection will involve a changed perspective, action, experimentation reviews and learning through one's experience. Reflection and reflective practice are terms that have become very familiar to contemporary nursing practice in the United Kingdom and other advanced countries ${ }^{[3]}$ but currently, the same concept is gradually evolving in nursing practice in Nigeria ${ }^{[4]}$ According to Burton ${ }^{[5]}$, reflection and reflective practices are terms that can engender a whole spectrum of reactions, ranging from positive enthusiasm to feelings of gross ambiguity and consternation. Reflection provides an excellent way for students to analyze care and increase their abilities to make clinical judgments. Reflective journaling therefore, is a strategy used often in clinical education to gain insight into students' critical thinking and professional development.

\section{Reflective journaling and reflective writing}

A reflective journal is a way of thinking in a critical and analytical way about a particular work in progress ${ }^{[6]}$. It shows how different aspects of the work interconnect. Reflective writing on the other hand is evidence of looking back at an event, idea, object, experience, process and so on. It involves analyzing and commenting on the object or process from different points of view using contemporary ideas and theories exploring and explaining the importance or relevance of the object or process, 
considering things that went wrong as well as successes, saying what the object, process or means to and saying how learning will influence the way we work ${ }^{[7]}$. According to Babcock University (BU) curriculum for the training of nursing students, the process of reflective journal writing was introduced to generic students from 200level and at 300level to direct entry nursing students respectively. The students are to journal on special posting areas during medical-surgical and Community Health posting. This is so because, reflection facilitates the integration of theory and practice and makes nurses critical thinkers and doers. This explains why the present study was designed to find out about the perception of reflective journaling during clinical posting among nursing students in BU. The objectives were to determine nursing students' perception of reflective journaling and to also find out the perceived meaning of reflective journal by the students.

\section{Literature review}

\section{Types of reflection}

Journals can be used to reflect on a range of issues and situations from numerous viewpoints and perspectives. RMIT (2006) ${ }^{[8]}$ lists six types of reflections.

Observations - at this stage, a student would write about what they actually saw or their viewpoint on a particular event.

Questions - upon reflection, the student could ask the question on what s/he has reflected upon.

Speculations-after thinking about the situation, the student could reflect.

Self-awareness - at this point a student may place himself or herself in the situation by considering the ramifications.

Integration of theory and ideas - by reflecting on theories or ideas about cultural norms, the student has connected the experience with what he or she has learned.

Critique - this is where the student may self-reflect on or "critique" the situation.

\section{The reflection cycle}

Reflecting is a cyclical process, where recording ones thoughts (reflecting) "leads to improvement and/or insight" ${ }^{,[8]}$. Improvement could mean progress, development, growth, maturity, enhancement, or any number of words which could imply change. In education, we want students to change for the better, to grow while learning and to mature into knowledgeable adults and the same thing is applicable during clinical posting. Recording what has happened, reflecting on processes and analyzing to improve deeper learning all can lead to new dimensions of students' inner selves. RMTI $(2006)^{[8]}$ described four cyclical process of reflection: Reflect (Think); Analyze (Explain and gain insight); New action; Record (What). Various cycle of reflective exist, what is common in most of them is the ability to evaluate and analyze an event. For the purpose of this study, only Gibb's Cycle of reflection is reviewed.

\section{Gibb's reflective cycle}

Model as cited by Dye, $\left(2011^{[9]}\right.$ acknowledges that personal feelings influence the situation and how one has begun to reflect on it. It builds on Boud's model by breaking down reflection into evaluation of the events and analysis and there is a clear link between the learning that has happened from the experience and future practice. Instead, other theorists have broken down the cycle into further stages, an example of which is Gibb's reflective cycle ${ }^{[10]}$. 

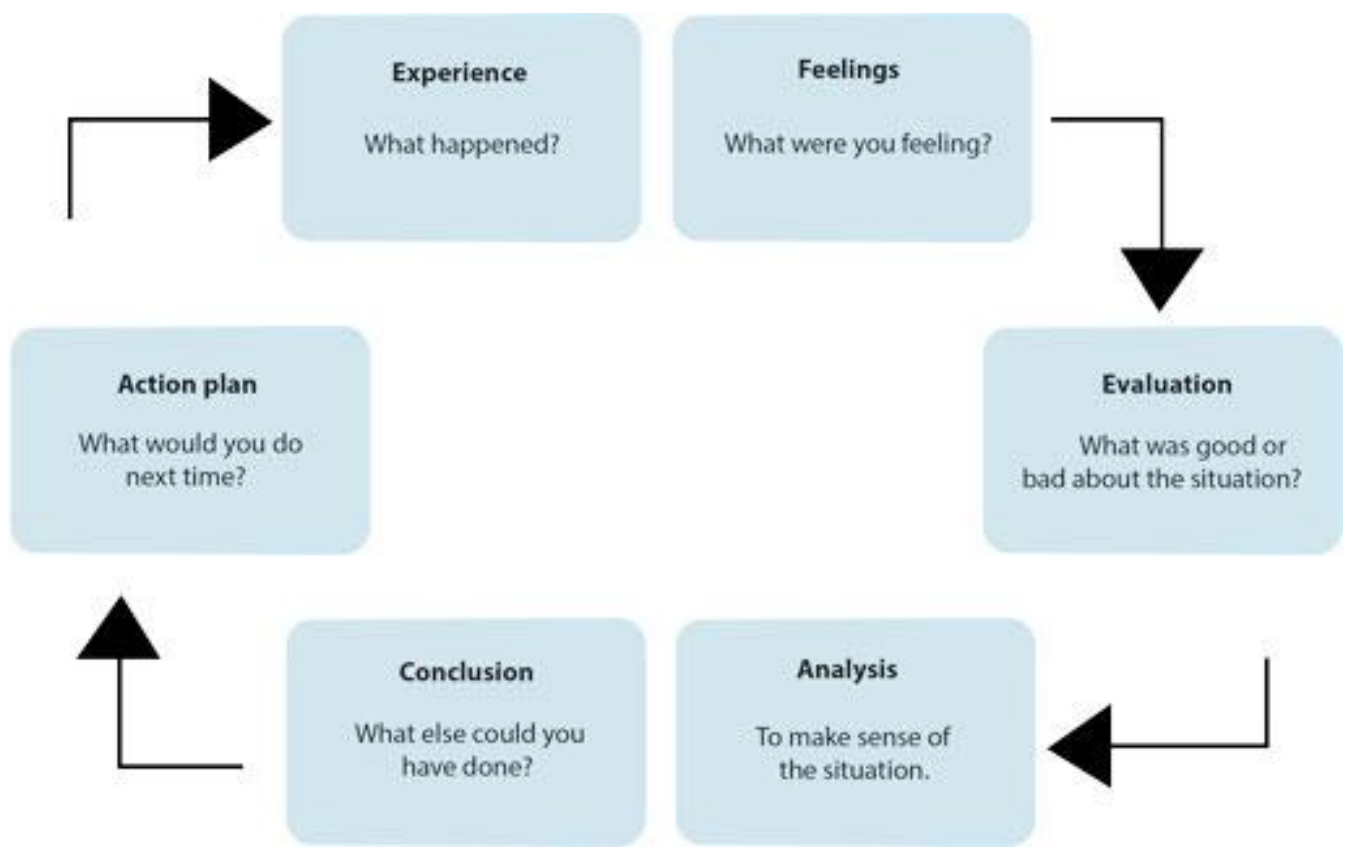

Figure 1. Gibb's reflective cycle (adapted from dye, 2011)

\section{Elements of the gibbs' reflective cycle}

Mantzoukas and Jasper ${ }^{[1]}$ explained that, Gibbs' model of reflection consists of six distinct steps namely: the description of what happened; the practitioner's feelings during the experience; the evaluation of what was good and bad about the experience; the analysis or sense making of the situation; the conclusions and potential alternatives in dealing with the situation, and; the action.

Stage 1: Description of the event-At this stage, the nursing student must describe in detail the event being reflected on. McMillan-Coddington and Weyers ${ }^{[12]}$ suggested that, powers of observation and ability to record the situation and associated events will be utilized. This includes responding to questions such as where she/he was; who else was there; why was he/she there; what was he/she doing; what were other people doing; what was the context of the event; what happened; what was his/her part in this; what parts did the other people play; what was the result. Bulman and Schutz ${ }^{[13]}$ however concluded that no judgments must be made at this stage, only a simple description. The students must be encouraged therefore, to tell their own stories in their own voice.

Stage 2: Feelings-At this stage, the student must try to recall and explore the reactions and emotions that were going on inside his/her mind, explaining why this event sticks in his/her mind? The following must be included: how he/she was feeling when the event started; what he/she was thinking about at the time; how did it make he/she feel; how did other people make he/she feel; how did he/she feel about the outcome of the event; what he/she thinks about it now ${ }^{[13]}$.

Stage 3: Evaluation- The student tries to evaluate or make a judgment about what has happened. Consider what was good about the experience and what was bad about the experience or what didn't go so well ${ }^{[13]}$.

Stage 4: Analysis-At this stage, the student must break the event down into its component parts so they can be explored separately. He/she may need to ask more detailed questions about the answers to the last stage. These must be included: what went well; what did he/she do well; what did others do well; what went wrong or did not turn out the way it should have; in what way did he/she or others contribute to this. Similarities and/or differences of his/her feelings compared to others can be described ${ }^{[13]}$.

Stage 5- Conclusion At this stage the issue is explored from different angles. In addition, the student must have a lot of information to base his/her judgment. It is here that he/she is likely to develop insight into his/her own and other people's behavior in terms of how they contributed to the outcome of the event ${ }^{[13]}$. The emphasis therefore, is on learning from an experience. During this stage the student should ask him/herself what s/he could have done differently. The student can make 
general or specific conclusions regarding the event ${ }^{[13]}$ and this indicates insight and maturity of the student.

Stage 6: Action Plan- During this stage, the student should think forward. Faced with the same event again what would he/she plan and do differently or would s/he be likely to do the same? This becomes very personal as the student decides on future encounters and own actions regarding same event/experience ${ }^{[13]}$.

\section{Methods}

\section{Study design}

A descriptive survey research design was adopted for the study to determine the participants' perception and perceived meaning of reflective journaling.

\section{Location and period of study}

The study was carried out between January to June, 2017 in Babcock University. Babcock University is a private Christian co-educational Nigerian University owned and operated by the Seventh-day Adventist Church in Nigeria. The University is located equidistant between Ibadan and Lagos ${ }^{[14]}$. It is a part of the Seventh-day Adventist education system, the world's second largest Christian school system ${ }^{[15]}$. The Nursing Science Department started in 1999 when Babcock University was established as the Health Sciences Department which ran two programs; Nursing Science and Public Health Education. The following Departments are under school of Nursing as contained in Student handbook, 2015-2017- Adult Health, Comunity Health, Marternal \& Child Health and Mental/Psychiartric Health.

\section{Sample size and sampling techniques}

Participants were drawn purposively from 400 and 500 level students in the School of Nursing, BU. The minimum sample size was determined using the Evan Morris sample size formula for small population ${ }^{[16]}$. A total sample size of 178 was used which includes margin for non-response. However, only 130 questionnaires were retrieved in good condition, sorted, coded and analyzed. Only students who have undergone clinical posting on Journaling met the inclusion criteria.

\section{Ethical clearance and informed consent}

The study protocol, the associated informed consent forms, and study-related documents such as participation, education and recruitment materials were all submitted to Babcock University Health Research Ethics Committee (BUHREC) for review. The study was conducted in full compliance with the protocol. There was close coordination between the researchers and BUHREC to track study progress. Every effort was made to protect participants' privacy and confidentiality.

\section{Instrument and data collection}

Interviewer administered questionnaire was used to collect data from the participants. The questionnaire captured socio-demographic characteristics like sex, age, mode of admission and level of study. Questionnaire on perception contained items such as 'I am able to correlate theory with practice', 'I am involved in critical thinking before journaling', 'I am able to redefine experiences and problems'. Some of the items on perceived meaning of journaling are: 'A journal is an instrument for practicing writing and thinking'; 'It is a mere listing of events', 'It is a personal record of life', 'It is a tool for documenting and accompanying students' actions.

\section{Data analysis}

The analysis of the data from the survey/questionnaire was performed using the SPSS 22.0 Descriptive statistics such as frequencies, simple percentage, mean and standard deviation tables were used to describe the data based on the objectives. 


\section{Results}

Table 1 reveals the results on perception of reflective journaling. To establish the status, the average modified Likert rating scale below was adopted.

Criterion Scoring of perception of Journaling as- 1.45= Lowperception;1.5-1.95= High Perception. The detailed result is given below.

Table 1. Perception of reflective journaling $\mathrm{N}=130$

Criterion Scoring of Perception of Journaling: $\mathrm{Yes}=2, \mathrm{No}=1$

\begin{tabular}{|c|c|c|c|c|}
\hline Items & Yes & No & Mean & Std. Deviation \\
\hline $\begin{array}{l}\text { I am able to correlate } \\
\text { theory with practice }\end{array}$ & $125(96.2)$ & $5(3.8)$ & 1.9615 & .19305 \\
\hline $\begin{array}{l}\text { My problem solving skill } \\
\text { have improved }\end{array}$ & $124(95.4)$ & $6(4.6)$ & 1.9538 & .21063 \\
\hline $\begin{array}{l}\text { I am able to redefine } \\
\text { experiences and } \\
\text { problems }\end{array}$ & $123(94.6)$ & $7(5.4)$ & 1.9462 & .22659 \\
\hline $\begin{array}{l}\text { I am able to make } \\
\text { proactive decisions and } \\
\text { take on the spot } \\
\text { corrective actions }\end{array}$ & $113(86.9)$ & $17(13.1)$ & 1.8692 & .33845 \\
\hline $\begin{array}{l}\text { I am able to use past } \\
\text { experiences to prevent } \\
\text { future occurrences }\end{array}$ & $124(95.4)$ & $6(4.6)$ & 1.9538 & .21063 \\
\hline $\begin{array}{l}\text { I am involved in critical } \\
\text { thinking before } \\
\text { journaling }\end{array}$ & 121(93.1) & $9(6.9)$ & 1.9308 & .25483 \\
\hline
\end{tabular}

Only 130 students participated fully and filled the questionnaire correctly in the study area out of 178 and the overall findings have shown a high perception towards reflective journal writing in the undergraduate nursing program in BU. The mean score of perception of reflective journaling was 1.93205. Most of the students were able to correlate theory with practice $(96.2 \%)$ with the mean of 1.9615. Of the 130 participants, only (4.6\%) said their problem solving skills did not improve. However, $(86.9 \%)$ of them were able to make proactive decisions and took on the spot corrective actions while journaling. The highest proportion, (95.4\%) of the respondents had been able to use past experiences to prevent future occurrences with mean score of 1.9538. Majority of the participants $(93.1 \%)$ said they were involved in critical thinking before journaling during clinical posting.

Table 2 reveals the results on perceived meaning of reflective journaling. To establish the status, the average modified Likert rating scale below was also adopted.

Criterion Scoring of Perceived Meaning of Journaling was- 1.45 = Low Perceived Meaning; 1.5 $1.95=$ High Perceived Meaning. 
DOI: $10.21522 /$ TIJNR.2015.03.02.Art017

ISSN: $2520-3126$

Table 2. Perceived meaning of journaling

\begin{tabular}{|c|c|c|c|c|c|}
\hline Options & No (1) & $\begin{array}{l}\text { Yes } \\
\text { (2) }\end{array}$ & \multirow[t]{2}{*}{ Mean } & \multirow[t]{2}{*}{ SD } & \multirow[t]{2}{*}{ Remark } \\
\hline Items & \multicolumn{2}{|c|}{ Frequency } & & & \\
\hline $\begin{array}{l}\text { A journal is an instrument } \\
\text { for practicing writing and } \\
\text { thinking }\end{array}$ & 120 & 10 & 1.923077 & 0.2675002 & $\begin{array}{l}\text { High Meaning } \\
\text { Perceived }\end{array}$ \\
\hline $\begin{array}{l}\text { It is a personal record of } \\
\text { your educational experience } \\
\text { in class }\end{array}$ & 103 & 27 & 1.792308 & 0.4072246 & $\begin{array}{l}\text { High Meaning } \\
\text { Perceived }\end{array}$ \\
\hline It is a mere listing of events & 44 & 86 & 1.338462 & 0.4750169 & $\begin{array}{l}\text { Low Meaning } \\
\text { Perceived }\end{array}$ \\
\hline It is a personal records of life & 77 & 53 & 1.407692 & 0.4933064 & $\begin{array}{l}\text { Low Meaning } \\
\text { Perceived }\end{array}$ \\
\hline $\begin{array}{l}\text { It is a tool for documenting } \\
\text { and accompanying students' } \\
\text { actions }\end{array}$ & 94 & 36 & 1.723077 & 0.449209 & $\begin{array}{l}\text { High Meaning } \\
\text { Perceived }\end{array}$ \\
\hline$\overline{~ T o t a l}$ & & & 8.184616 & 2.092257 & \\
\hline
\end{tabular}

Criterion Mean Score: 8.184616

Criterion SD Score: 2.092257

Data evidences in table 2 revealed that the status of perceived meaning of reflective journaling of nursing students' clinical learning and practice is high. This inference is evident in the fact that overall criterion weighted mean score (1.805147) is greater than average Likert scale of 1.5.In terms of item by item analysis 'A journal is an instrument for practicing writing and thinking 'with mean and standard deviation criterions scores 1.923077and 0.2675002 ranks highest based on the mean score rating. This is followed by 'It is a tool for documenting and accompanying' (mean = 1.723077); 'It is a personal records of life' (mean = 1.592308); 'It is a personal record of your educational experience in class' $($ mean $=1.407692)$; and 'It is a mere listing of events' $($ mean $=1.338462)$.

\section{Discussion}

The objectives of this study were to determine the nursing students' perception of reflective journaling on clinical posting and to also find out their perceived meaning of reflective journaling. The discussion presented here followed the sequence of the stated objective.

\section{Perception of reflective journaling}

The study revealed that a significantly higher proportion of the participants showed a high perception towards reflective journal writing in the undergraduate nursing program in BU. The participants were able to correlate theory with practice, made proactive decisions and took on the spot proactive actions. Participants also affirmed their problem solving skills have improved and confirmed that, reflective writing was useful to them. This finding corroborates the results in a similar study conducted by Mahlanze ${ }^{[17]}$ among undergraduate nursing students at the Durban University of Technology. The author evaluated the use of guided reflective journals by assessing perception and the levels of reflection of the undergraduate nursing students during clinical learning and practice ${ }^{[17]}$ It was reported in her study that the participants generally expressed writing of reflective journals as a valuable tool in professional, personal development as well as clinical learning ${ }^{[17]}$. Similarly, the current study also support the findings from Henter and Indreica ${ }^{[18]}$ on reflective journal writing as a metacognitive tool among freshmen in University of Brasov, Romania ${ }^{[18]}$. In a reflective writing, students record their thoughts on the level of awareness involved in their cognitive labor and comment on their learning decisions ${ }^{[18,19,20]}$. 


\section{Perceived meaning of journaling}

The study showed that participants understood the perceived meaning of journaling to a reasonable extent. Data evidences in table 2 revealed that the status of perceived meaning of reflective journaling of nursing students' clinical learning and practice is high. This inference is evident in the fact that overall criterion weighted mean score (1.805147) is greater than average likert scale of 1.5. However, in terms of item by item analysis a higher proportion of the respondents said a reflective journal is an instrument for documenting and accompanying personal record of life and is a mere listing of events. This notion was wrong as only diary fall in this category. Spring ${ }^{[21]}$ had earlier differentiated between journal and diary.

\section{Conclusion/ recommendation}

This study concludes that students perceive reflective journaling as a useful tool for problem solving approach in nursing profession. Through a reflective journal, one can explore the ways of using learning strategies consciously and adapting the learning process to the concrete situations during clinical postings. Levels of reflection and development of reflective journaling or writing should therefore be greatly enhanced if reflective practice among clinical nurses must be achieved. To that effect, Olson and Johnson ${ }^{[22]}$ emphasize writing journals should become a weekly routine among students in order to meet its purpose, along with a descriptive feedback offered each time by the teacher ${ }^{[22]}$.

\section{References}

[1]. Bulman C., and Schutz S. 2008. Reflective practice in nursing. (4th edition. USA: Blackwell Publishing Ltd) Adventist News Network, 2009. Commentary Opinion, 2015.

[2]. Boud D., Using Journal writing to enhance reflective practice, New directions for adult and continuing education, 90, 2001, 9-17.

[3]. Burton A. J., Reflection, Nursing Practice and Education Panacea?, Journal of Advanced Nursing,31(5), 2000, 1009-1017.

[4]. Dewey J., How We Think. A Restatement of the Relation of Reflective Thinking to the Educative Process.( Dc Health Boston, 1993).

[5]. Dye V., 'Reflection, Reflection, Reflection. I'm thinking all the time, why do I need a theory or model of reflection? in McGregor, D. and Cartwright, L. Developing Reflective Practice: A guide for beginning teachers, Open University Press. 2011.

[6]. Enuku C. A. and Evawoma- Enuku U., the Need to Incorporate Reflective Practice into Nursing Education Curriculum In Nigeria. Journal of Nursing and Health Science 1(2), 2013, 57-62.

[7]. Gibbs G., The reflective cycle. Oxford: Further Education Unit, Oxford Polytechnic, 1988.

[8]. Gillett A., Hammond A., and Martala M, Successful academic writing (Harlow: Person Education Limited 2009).

[9]. Henter R., Indreica E. S., Reflective Journal Writing As a Metacognitve Tool International Conference of Scientific Paper Afases Brasov, 2014.

[10]. Huang J., Meta-cognition training in the Chinese University Classroom: An Action Research Study. Educational Action Research, 13(3), 2005, 413 - 434.

[11]. Reedand B., I. Ground, Philosophy for nursing. (Arnold, London, 1997).

[12]. McMillan-Coddington D., and Weyers J., Reflection through journal writing to educate registered nursing students on patient care. Teaching and Learning in Nursing, 8(2), 2013, 63-67.

[13]. Morris E., Sampling from Small Populations. www.google .com. accessed 17th March, 2017.

[14]. Papaleontiou - Louca E., Metacognition and Theory of Mind. (Cambridge Scholars Publishing, 2008).

[15]. Mahlanze H. T., Evaluation of the use of guided reflective journals during clinical learning and practice by undergraduate nursing students at the Durban University of Technology. Dissertation submitted in fulfilment of the requirements for the Degree of Master of Technology in Nursing in the Faculty of Health Sciences at the Durban University of Technology. 2014.

[16]. Olson J., C and Johnson S., Implementing journal writing in grade 8, Academic Research International, Part-II: Social Sciences and Humanities, 3(3), 2012. 
DOI: $10.21522 /$ TIJNR.2015.03.02.Art017

ISSN: $2520-3126$

[17]. Musah K. T., Okueso G. O., Ojo P. A., and Awodiya M.O., Influence of Reflective Journaling on Students' Clinical Learning and Practice a paper presented at the Department Seminar, Kwara State University, Malete, Nigeria. July, 2017.

[18]. RMIT University, Study and Learning Centre, (Melbourne, Australia. Reflective journals 2006

[19]. S. Mantzoukas, and M.A. Jasper. Reflective practice and daily ward reality: a covert power game. Issues in Clinical Nursing, 13(8), 2004, 925.

[20]. Spring Spring. A guide for writing a "reflective journal" (Adapted from Professor Wayne Iwaoka, the University of Hawaii at Manoa) SMS491/EDW472 Karp-Boss, Weller and Boss, 2007. 